\title{
Suprachiasmatic Nucleus Clock Time in the Mammalian Circadian System
}

\author{
H. OKAMURA \\ Department of Systems Biology, Graduate School of Pharmaceutical Sciences, \\ Kyoto University, Kyoto 606-8501, Japan, and Division of Molecular Brain Science, \\ Graduate School of Medicine, Kobe 650-0017, Japan
}

\begin{abstract}
The integration of time from gene to system levels is an exciting feature of circadian biology. In mammals, clock cells in the suprachiasmatic nucleus (SCN) generate time by an autoregulatory transcription-(post)translational feedback loop. Clock activity in the SCN neurons is expressed as activity-dependent electric signals, which are coupled to those of other SCN neurons. The SCN spreads the time signals in a form of synchronized nerve impulses to central parasympathetic nuclei (e.g., dorsal motor nucleus of the vagus) and central sympathetic nuclei (e.g., intermediolateral cell column of the spinal cord). The vagal nerve innervates gastrointestinal and respiratory organs. Sympathetic signals to the adrenal gland are converted to hormonal (glucocorticoid) signals. Glucocorticoids released into the bloodstream bind to glucocorticoid receptors of peripheral organs, activate the mammalian Perl gene in systemic cells, and reset the time of body clocks. Thus, the SCN-evoked time generated by specific genes localized to the SCN is converted to neuronal and hormonal signals and synchronizes the clocks in the whole body.
\end{abstract}

\section{INTRODUCTION}

The discovery of mammalian clock genes and the core clock machinery in most organs has raised the possibility that virtually 60 trillion cells of the human body have oscillating ability using the same transcription-based core loop of clock genes (Balsalobe et al. 1998; Yagita et al. 2001; Schibler and Sassone-Corsi 2002). However, clock oscillation in the body is abolished after the lesion of the hypothalamic suprachiasmatic nucleus (SCN), although the ablation of any other region cannot abolish the rhythm (Moore and Eichler 1972; Stephan and Zuker 1972). Thus, only this specialized brain locus can work as a system clock. The special ability of the SCN for rhythm generation is also supported by transplantation or gene-rescue studies (Ralph et al. 1990; Sujino et al. 2003; McDearmon et al. 2006). Here, we describe the molecular mechanism that determines how time is generated in SCN cells and is tuned and transmitted to the whole body.

\section{CELLULAR MOLECULAR OSCILLATOR}

The SCN is composed of thousands of clock oscillating cells (Klein et al. 1991; Ibata et al. 1997; Yamaguchi et al. 2003). In each clock cell, rhythm is first generated by the intracellular molecular oscillator. This core oscillator is composed of an autoregulatory transcription(post)translation-based feedback loop involving a set of clock genes, which was first proposed in the Drosophila oscillating gene period (Hardin et al. 1990). Following this basic concept, a number of clock genes have been identified in mammals since the discovery of mammalian Per and Clock genes in 1997. It is now speculated that positive factors CLOCK and BMAL1 form heterodimers that bind E-box elements to activate Perl and Per2 transcription; then, negative factors PER1/PER2 dimerize with CRY1/CRY2 feedback in a delayed fashion to inhibit CLOCK/BMAL1 activity (Fig. 1) (Reppert and Weaver 2002; Okamura 2004). As a general rule of transcription machinery, it was recently confirmed that circadian transcription accompanies chromatin remodeling (Etchegaray et al. 2003; Doi et al. 2006).

Furthermore, there is growing evidence that clock proteins are regulated dynamically in both spatial (nuclear and cytoplasmic) and temporal (production and degradation) dimensions. The main clock oscillatory protein PER2 shuttles between the nucleus and the cytoplasm by using their own nuclear localization signals (NLS) and nuclear export sequences (NES) (Yagita et al. 2002). Shuttling of BMAL1 is also reported, and it has been demonstrated that the nuclear translocation of CLOCK is accompanied by BMAL1 (Kondratov et al. 2003; Kwon et al. 2006). During spatial transportation, clock proteins receive posttranscriptional modifications and targeted destruction (Gallego and Virshup 2007). Is transcriptional regulation or posttranslational regulation more important for the generation of cyclicity? By applying the Tet-Off and Flp-In system to a fibroblast cell line, we demonstrated that the intracellular endogenous clock system has the ability to modify the Per 2 gene posttranscriptionally to make PER2 proteins oscillate without its coding mRNA cycling (Yamamoto et al. 2005; Fujimoto et al. 2006). However, to obtain robustness and continuity, rhythmic regulation seems to be prerequisite at both the transcriptional and posttranslational regulation levels.

\section{CELL CLOCK TO CELL FUNCTION}

The cell clock coordinates the timing of the expression of a variety of genes with specific cellular functions. These so-called clock-controlled genes $(c c g)$ are rhythmically regulated by the core clock loop with their E-box, D- 


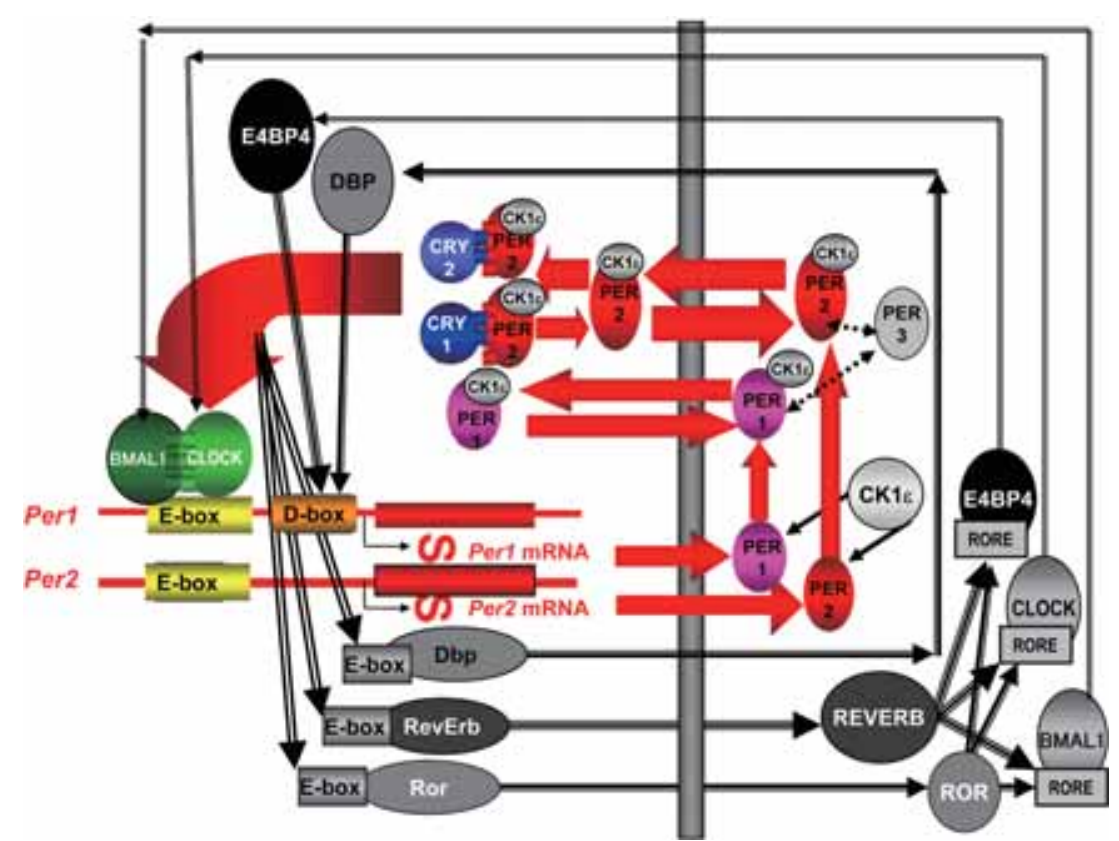

Figure 1. Core oscillatory loop of the mammalian circadian clock genes. The BMAL1/CLOCK heterodimer binds to the E box of the Per1 and Per2 genes to accelerate their transcription. PER2 protein is produced in the cytoplasm and then phospholylated by casein

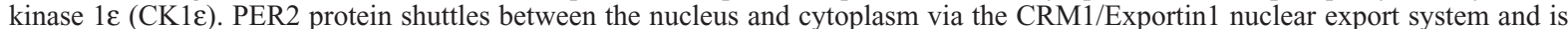
stabilized by the binding of CRY1 or CRY2. BMAL1/CLOCK also binds to the E box in clock-controlled genes $(c c g)$ and accelerates their transcription. The core negative autoregulatory feedback loop provided by Per 1 and Per 2 runs on, accompanying the move of an accessory DBP/E4BP4, ROR, and REVERB protein loop.

box, and RORE regions. E box and D box are related to genes expressed during the day (Mitsui et al. 2001), and RORE is related to genes expressed at night. Vasopressin, albumin, cholesterol $7 \alpha$ hydroxylase, and cytochrome P450 are examples, and gene array studies have reported that about $5-10 \%$ of expressed genes show circadian rhythm (Panda et al. 2002; Storch et al. 2002). Among these $c c g$ genes, it is interesting to note that there are bZIP (basic leucine zipper) transcription factors ( $D b p, E 4 b p 4)$ and nuclear receptors Ror (Ror $\alpha, \operatorname{Ror} \beta, \operatorname{Ror} \gamma)$ and Rev$\operatorname{Erb}(\operatorname{RevErb} \alpha, \operatorname{RevErb} \beta)$. These specialized genes form the subloops of core clock gene oscillation, which will contribute to the robustness and stability of the rhythm of core clock oscillation (Fig. 1).

Why is circadian time information needed for cellular function? The proteins are key players in cellular function, and for single functional proteins $(5-30 \mathrm{~nm}$ in diameter), cell space is huge (10-50 $\mu \mathrm{m}$ in diameter). Thus, for proteins to perform effective cellular functions, cellular reactions should be organized in time and space. The intracellular clock oscillating loop may be useful in controlling cellular events for proper and adequate time organization. One example is the cell cycle. There is substantial evidence that circadian rhythms affect the timing of cell divisions in vivo (Bjarnason and Jordan 2000). Because some of these mitotic rhythms were shown to persist in constant darkness, it was concluded that they might be under the control of an endogenous clock. Matsuo et al. (2003) demonstrated that the circadian clock controls the $\mathrm{G}_{2}$-to-S transition via the regulation of WEE1. Circadian clock signals may also control the timing of many basic cellular metabolisms yet to be elucidated.

\section{SYNCHRONY OF SCN CLOCK CELLS}

Perl-luc study of the SCN slice culture at microscopic resolution enables analysis of clock gene transcription at the cellular level (Yamaguchi et al. 2003). These SCN cells showed robust transcription rhythms with a period length of approximately 24 hours, with several hundreds of cells expressing Perl genes synchronously. Moreover, the individual oscillatory cells are arranged topographically: The phase leader with a shorter period length is located in the dorsomedial periventricular part of the SCN. A protein synthesis inhibitor (cycloheximide) sets all of the cell clocks to the same phase and, following withdrawal, intrinsic interactions among cell clocks reestablish the stable program of gene expression across the assemblage. Tetrodotoxin, which blocks action potentials, not only desynchronizes the cell population, but also suppresses the level of clock gene expression, demonstrating that neuronal network properties dependent on action potentials have a dominant role both in establishing cellular synchrony and in maintaining spontaneous oscillations across the SCN. Thus, the cell-rhythm oscillation generated by the core clock oscillatory loop is coupled and amplified by the ordered cell-cell communications in the SCN.

Does this transcriptional rhythm really occur in living, free-moving animals? An optical fiber insertion just on the SCN of living animals enables us to monitor the Per 1luc transcription activity in living animals (Yamaguchi et al. 2001). Using this system, we were able to continuously record light emission from the SCN of Per1-luc transgenic mice in vivo under constant dark conditions. The 

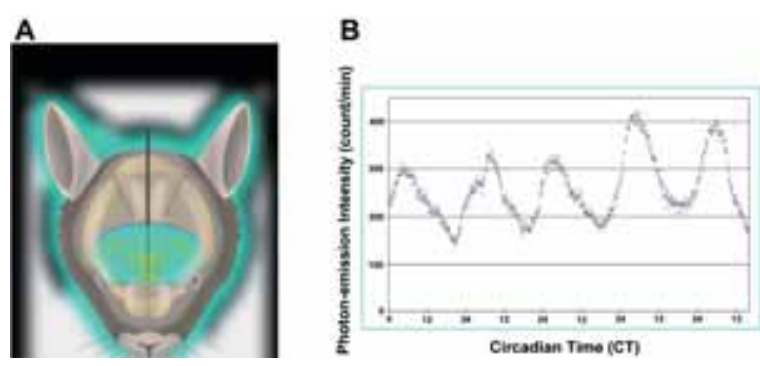

Figure 2. Monitoring gene expression of the $\mathrm{SCN}$ in living freely moving animals. (A) An illustration showing the experiment monitoring gene expression of SCN in living mice brain. A polymer optical fiber $(500 \mu \mathrm{m}$ in diameter; 0.5 numerical aperture) is inserted just above the SCN of a mPerl-luc transgenic mouse. The other end of the optical fiber (not shown) is connected to a photomultiplier tube operating as part of a photoncounting apparatus. The luciferase substrate luciferin dissolved in artificial cerebrospinal fluid is continuously infused through a lateral ventricle at a rate of $15 \mu \mathrm{l}$ /hour. Luminescence was recorded under constant dark conditions. $(B)$ Circadian fluctuation of luminescence in the SCN. One dot represents an average of the value of 5 minutes. Hatched and closed bars at the bottom of the figure represent subjective day and subjective night, respectively. This model system enables real-time gene expression to be monitored in the intact brain under physiological conditions. ( $A$, drawn by Seiichi Takekida; $B$, reprinted, with permission, from Yamaguchi et al. 2001 [C Nature Publishing Group].)

luminescence showed a clear circadian fluctuation (Fig. 2 ), with a 1.5- to 2.5-fold amplitude and peaks and troughs at circadian time (CT) 4-6 and CT15-20, respectively (where CT0 is subjective dawn and CT12 is subjective dusk). Considering the expression profiles of Perl mRNA in the SCN (Shigeyoshi et al. 1997), the phase lag between luciferase mRNA and luminescence was only 0-2 hours. An important finding of this study is that the net expression of gene activity fluctuates in living animals, although with a substantial difference of circadian phase at each cell level (Yamaguchi et al. 2003). Moreover, luciferase peaks at subjective morning and troughs at subjective night are very similar to electric activity rhythm (Inouye and Kawamura 1979). Thus, the net clock gene expression reflects net electrical activity, which will be widely conducted to other brain areas.

\section{SCN OUTPUTS AND REGULATION OF PERIPHERAL ORGANS}

Do SCN signals really drive circadian clocks in the peripheral organs? Sujino et al. (2003) reported that SCN grafts from wild-type mice into mice that were "doubly arrhythmic," due to being both SCN-lesioned and Cry 1/Cry2 double-knockout mice, restored circadian locomotor activities. Grafts should include SCN tissue, because grafts from the cerebral cortex cannot restore rhythms to SCN-ablated animals (Sujino et al. 2003). Similarly, McDearmon et al. (2006) reported that the behavioral rhythm of arrhythmic BMAL1 knockout mice was normalized by brain-specific rescue but not by muscle-specific rescue. These studies strongly suggest that peripheral clocks are unnecessary for the generation and expression of behavioral rhythms and that the SCN is the generator of brain rhythms. The dominance of the SCN clock over peripheral oscillators was also demonstrated by Pando et al. (2002) using grafts from animals with genetically altered period lengths.

By what route are time signals conveyed from the SCN to peripheral tissues? More than a quarter of a century ago, autonomic changes of circadian rhythms were shown in sleep/wake cycles, as well as in cardiovascular, respiratory, and gastrointestinal functions, although the mechanisms of these changes are unknown. Most outputs of SCN neurons terminate to the subparaventricular zone (Klein et al. 1991). From there, signals are transmitted to central sympathetic (e.g., intermediolateral cell column) and parasympathetic (e.g., dorsal motor nucleus of the vagus) nuclei (Fig. 3) (Buijs and Kalsbeek 2001).

Parasympathetic vagal innervation is dominant in gastrointestinal and respiratory tracts. Bando et al. (2007) reported the existence of a clock-gene-mediated oscillating system in the respiratory gland whose rhythm was abolished after ablation of the SCN. To address the role of the vagal nerve on these respiratory clocks, these authors performed a unilateral vagotomy and found that circadian expression of mucin and PER2 protein levels was abolished in the (operated) ipsilateral side of the submucosal glands, although clear rhythm was detected in the (intact) contralateral side (Fig. 4). Because transcripts of a mucinencoding gene did not show circadian rhythm, its regulation may not be at the level of production. Because muscarinic acethylcholine receptor genes $\mathrm{Chm} 2, \mathrm{Chm} 3$, and $\mathrm{Chm} 4$ are under the control of the circadian clock, mucin will be rhythmically released through these receptors. Thus, in airway organs, the vagal nerve is the key mediator conveying SCN circadian signals to the airway glands.

Sympathetic regulation of clock genes is initially found in the liver. Terazono et al. (2003) clearly demonstrated that chemical sympathectomy damped clock gene oscillation and that adrenergic drug treatment resets the rhythm. The above finding suggests that both sympathetic and parasympathetic regulation convey SCN rhythm to visceral organs.

\section{CONVERSION OF NERVE IMPULSE TO HORMONE SURGE IN THE ADRENAL GLAND}

In the analysis of the sympathetic effect of clock genes on visceral organs, we devised the macroimaging of Perl$l u c$ mice with a two-dimensional photon-counting camera, which enabled the detection of light-induced gene expression at each organ at one glance. Ishida et al. (2005) have revealed that light preferentially increases the transcription of Perl in the adrenal gland without any change in other visceral organs such as liver and kidney (Fig. 5).

Adrenal gene expression is not limited to the Perl gene; DNA microarray analysis has demonstrated 156 upregulated genes and 39 down-regulated genes. Because adrenal gene expression was abolished after SCN lesioning or by the transaction of the adrenal sympathetic nerve, light signals were conveyed to the adrenal gland via the SCN-sympathetic nerve route. More interestingly, this gene expression accompanies the surge of plasma and 


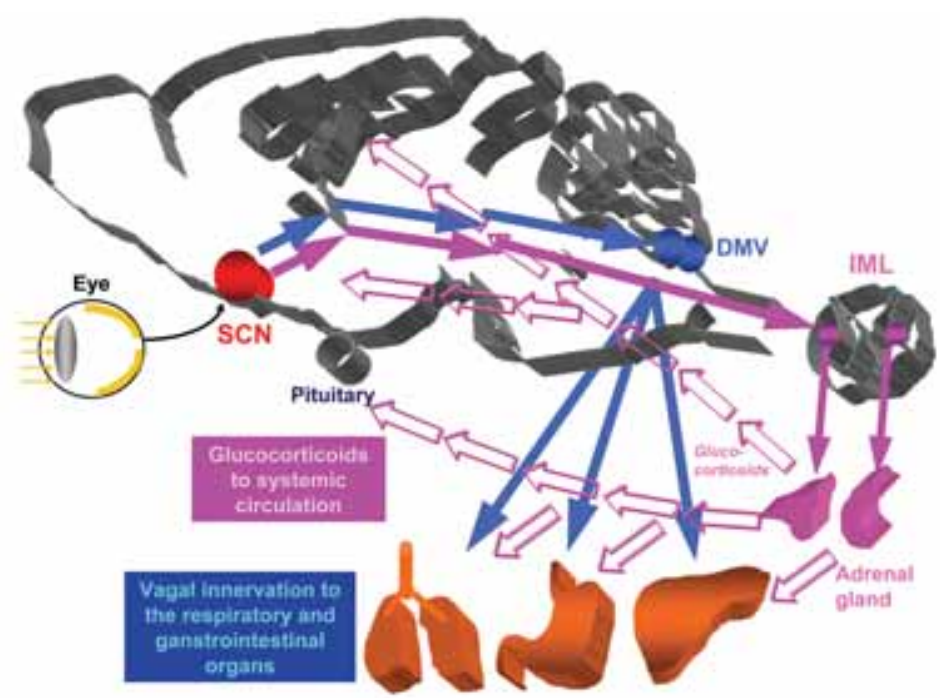

Figure 3. SCN-autonomic outputs. SCN signals are finally transmitted to the central sympathetic intermediolateral (IML) cell column of the spinal cord or to the central parasympathetic dorsal motor nucleus of the vagus (DMV). Signals to the adrenal gland are converted to glucocorticoid signals and spread to whole body by the blood vessels.

brain corticosterone levels after 60-90 minutes without activation of the hypothalamus-pituitary-adrenal (HPA) axis. This activation was completely different from the usual stress reaction: Corticosterone as well as ACTH levels were immediately increased (i.e., $2-5$ minutes) to their maximal levels. The larger time lag of the response of corticosterone (60 minutes) also suggests a different mechanism in this process.

On which target does corticosterone act? The released corticosterone may bind to the glucocorticoid receptor
(Balsalobre et al. 2000) and activate the Perl gene in systemic cells (Koyanagi et al. 2006), which will reset the time of the peripheral clock. Thus, the light-evoked corticosterone may have a role in transmitting environmental light signals to internal organs. In this light-induced situation, the SCN-sympathetic-adrenal system will also be used for the generation of circadian plasma glucocorticoid levels peaking at dawn. Thus, the adrenal gland acts as a transducer of SCN clock time from nerve impulse to hormone surge in the circadian timekeeping system.

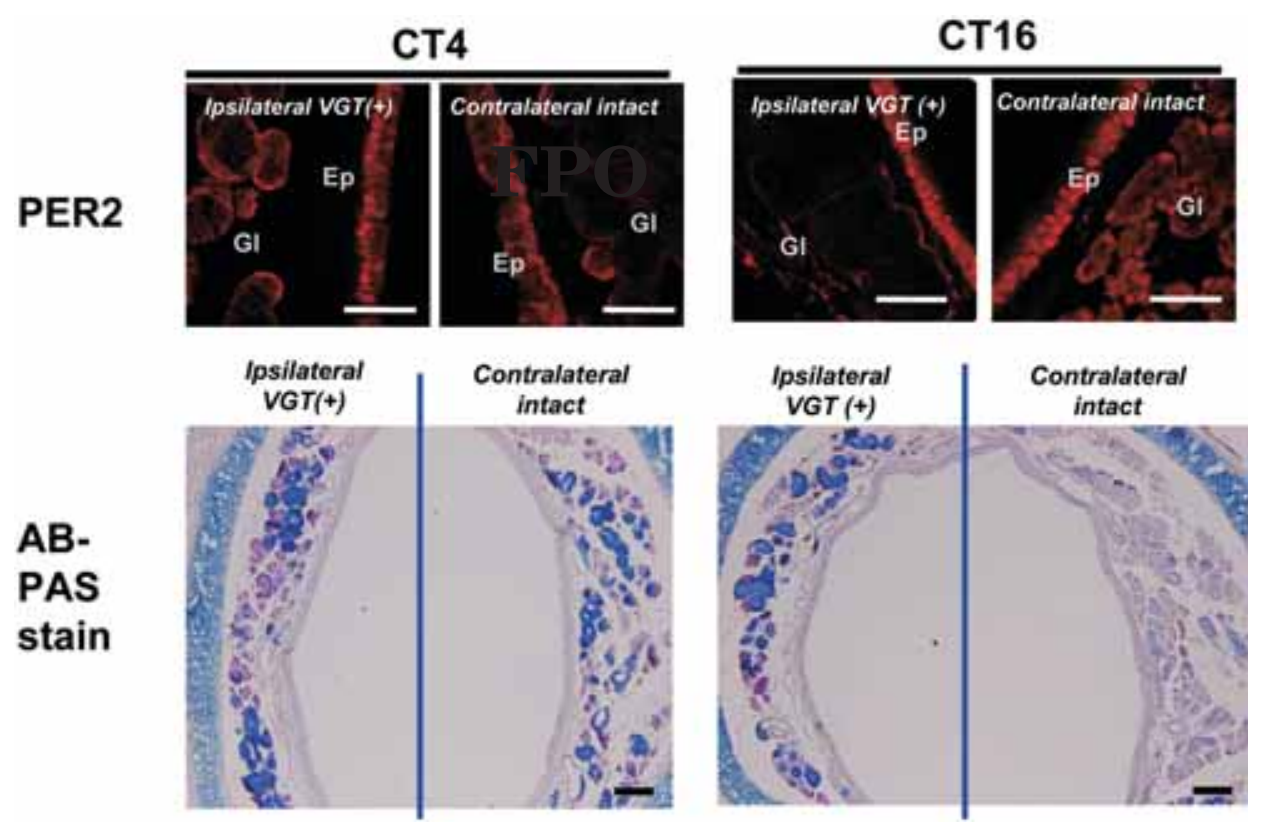

Figure 4. Vagotomy-induced changes in mucin levels and clock gene expression. (Top) Immunocytochemical detection of the PER2 protein at CT16 in the ipsilateral vagotomized $(\mathrm{VGT}[+])$ and contralateral intact side of the trachea. Note the rhythmic expression of PER2 in the submucosal gland at the intact contralateral side. (Bottom) Mucin levels (Alcian blue/PAS staining) at CT4 and CT16 in the trachea of C57BL/6 mice. Bar, $100 \mu \mathrm{m}$. (Reprinted, with permission, from Bando et al. 2007 [C Society for Neuroscience].) 

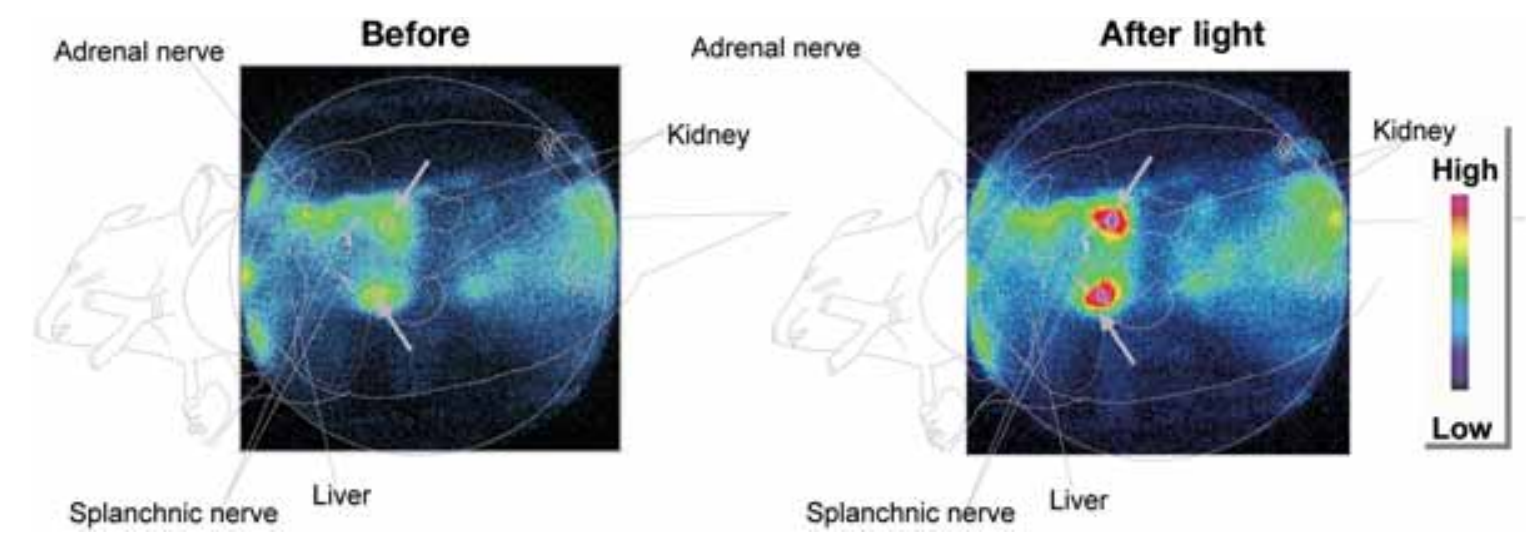

Figure 5. Light-induced Perl-luc luminescence in the adrenal gland. Luciferase bioluminescence in the abdomen of Perl promoterluciferase (Perl-luc) transgenic mice before and after 60-minute light exposure. Note the high level of expression of luciferase luminescence in the adrenal gland (arrows) after light exposure. (Reprinted, with permission, from Ishida et al. 2005 [C Elsevier].)

\section{SCN-GENE PROJECT FOR CIRCADIAN STUDY}

As shown above, the mammalian circadian system is designed to integrate SCN clock time to body clock time. However, there has been little effort to isolate clock genes themselves from this nucleus. The only trial has been the DNA microarray analysis of SCN picked up by the brain microdissection technique applied to sliced brain (Panda et al. 2002). However, this technique has serious methodological problems because SCN is a very tiny nucleus, and contamination of adjacent brain structures (preoptic area, anterior hypothalamic area, retrochiasmatic area, and optic chiasma) in the tissue is inevitable.

We are studying the gene involved in the ubiquitin-proteasome system. We are interested in this system because we found that PER2 and CRY proteins were easily ubiquitinated and CRY-PER heterodimerization stabilized PER (Yagita et al. 2002) in the analysis of the fibroblast cell line having the core component of the biological clock (Yagita et al. 2001). Recently, F-box E3 ubiquitin ligase FBXL3 was isolated as the specific ligase bound to CRY1 and CRY2 proteins (Busino et al. 2007; Godinho et al. 2007; Siepka et al. 2007). Among nine genes (Ubce5, UbcM4, Ube2v, Ube2d2, UchL1, UchL3, Ubp41, $U f d 1 L, \beta-\operatorname{Tr} C P$ ) having rhythmicity in a previously published DNA microarray study (Panda et al. 2002), we found that most of these enzymes were only faintly expressed in the SCN by in situ hybridization except for ubiquitin-conjugating enzyme 5 (Ubce5) and ubiquitin carboxy-terminal hydrolase L1 (UchL1), a dominant deubiquitinating salvaging enzyme (Dong et al. 2005). Thus, the microarray technique presently available does not strictly represent the gene profile of the SCN itself.

To overcome this problem, we began a project to isolate clock-associated genes from the SCN by histological screening (the SCN-Gene Project). DNA microarray (Affimetrix: GeneChip Mouse Genome 430 2.0 Array) analysis identified 12,379 genes. To determine whether these genes were really expressed in the SCN, we screened them by using in situ hybridization sampled sub- jectively during day and night. Genes that were highly and specially expressed in the SCN were selected and targeted in the next step, and the circadian phenotype of the mice was characterized.

Despite previous studies focusing on rhythmic gene expression, our project does not exclude constantly expressed genes, because we believe that constancy does not exclude involvement from rhythm generation. The feasibility of this project is supported by the finding that all known rhythm mutants have some defects in the SCN. In other words, genes expressed in the SCN are possibly involved in rhythm generation. Because the expressed gene number is limited, the SCN-Gene Project is expected to isolate a new clock gene.

\section{CONCLUSIONS}

The SCN is a small nucleus, occurring in pairs, located just above the optic chasma. It is astonishing that only about 10,000 of the oscillating cells in the SCN convey standard time to other brain regions and/or whole bodies. Gene expression and cell function in the SCN are specialized to generate circadian time. It is astonishing that Per1, Per2, Cry1, Cry2, VIP, and others that have profound effects on circadian rhythms are strongly and specifically expressed in this nucleus. We began a project to isolate new clock genes expressed in the SCN by histological analysis using the in situ hybridization technique. The SCN will be a link to analyze the integration mechanism of "time" in a vertical arrangement, providing a bridge between single genes and the living organism as a whole.

\section{ACKNOWLEDGMENTS}

This work was supported in part by The Scientific Grant of the 21st Century COE Program, and The Special Promotion Funds from Ministry of Education, Culture, Sports, Science, and Technology of Japan. 


\section{REFERENCES}

Balsalobre A., Damiola F., and Schibler U. 1998. A serum shock induces circadian gene expression in mammalian tissue culture cells. Cell 93: 929.

Balsalobre A., Brown S.S.A., Marcacci L., Tronche F., Kellendonk C., Reichardt H.M., Schulz G., and Schibler U. 2000 . Resetting of circadian time in peripheral tissues by glucocorticoid signalling. Science 289: 2344.

Bando H., Nishio T., van der Horst G.T.J., Masubuchi S., Hisa Y., and Okamura H. 2007. Vagal regulation of airway clocks in mice. J. Neurosci. 27: 4359.

Bjarnason G.A. and Jordan R. 2000. Circadian variation of cell proliferation and cell cycle protein expression in man: Clinical implications. Prog. Cell Cycle Res. 4: 193.

Buijs R.M. and Kalsbeek A. 2001. Hypothalamic integration of central and peripheral clocks. Nat. Rev. Neurosci. 2: 521.

Busino L., Bassermann F., Maiolica A., Lee C., Nolan P.M., Godinho S.I., Draetta G.F., and Pagano M. 2007. SCFFbxl3 controls the oscillation of the circadian clock by directing the degradation of cryptochrome proteins. Science 316: 900.

Doi M., Hirayama J., and Sassone-Corsi P. 2006. Circadian regulator CLOCK is a histone acetyltransferase. Cell 125: 497.

Dong X., Yagita Y., Zhang J., and Okamura H. 2005. Expression of ubiquitin-related enzymes in the suprachiasmatic nucleus with special reference to ubiquitin carboxy-terminal hydrolase UchL1. Biomed. Res. 26: 43.

Etchegaray J.P., Lee C., Wade P.A., and Reppert S.M. 2003. Rhythmic histone acetylation underlies transcription in the mammalian circadian clock. Nature 421: 177.

Fujimoto Y., Yagita K., and Okamura H. 2006. Does mPER2 protein oscillate without its coding mRNA cycling?: Posttranscriptional regulation by cell clock. Genes Cells 11: 525 .

Gallego M. and Virshup D.M. 2007. Post-translational modifications regulate the ticking of the circadian clock. Nat. Rev. Mol. Cell Biol. 8: 139.

Godinho S.I., Maywood E.S., Shaw L., Tucci V., Barnard A.R., Busino L., Pagano M., Kendall R., Quwailid M.M., Romero M.R., O'neill J., Chesham J.E., Brooker D., Lalanne Z., Hastings M.H., and Nolan P.M. 2007. The after-hours mutant reveals a role for Fbx13 in determining mammalian circadian period. Science 316: 897.

Hardin P.E., Hall J.C., and Rosbash M. 1990. Feedback of the Drosophila period gene product on circadian cycling of its messenger RNA levels. Nature 343: 536.

Ibata Y., Tanaka M., Tamada Y., Hayashi S., Kawakami F., Takamatsu T., and Okamura H. 1997. The suprachiasmatic nucleus: A circadian oscillator. Neuroscientist 3: 215.

Inouye S.-I.T. and Kawamura H. 1979. Persistence of circadian rhythmicity in a hypothalamic 'island' containing the suprachiasmatic nucleus. Proc. Natl. Acad. Sci. 76: 5962.

Ishida A., Mutoh T., Ueyama T., Bando H., Masubuchi S., Nakahara D., Tsujimoto G., and Okamura H. 2005. Light activates the adrenal gland: Timing of gene expression and glucocorticoid release. Cell Metab. 2: 297.

Klein D.C., Moore R.Y., and Reppert S.M. 1991. Suprachiasmatic nucleus: The mind's clock. Oxford University Press, New York.

Kondratov R.V., Chernov M.V., Kondratova A.A., Gorbacheva V.Y., Gudkov A.V., and Antoch M.P. 2003. BMAL1-dependent circadian oscillation of nuclear CLOCK: Posttranslational events induced by dimerization of transcriptional activators of the mammalian clock system. Genes Dev. 17: 1921.

Koyanagi S., Okazawa S., Kuramoto Y., Ushijima K., Shimeno H., Soeda S., Okamura H., and Ohdo S. 2006. Chronic treatment with prednisolone represses the circadian oscillation of clock gene expression in mouse peripheral tissues. Mol. Endocrinol. 20: 573.

Kwon I., Lee J., Chang S.H., Jung N.C., Lee B.J., Son G.H., Kim K., and Lee K.H. 2006. BMAL1 shuttling controls transactivation and degradation of the CLOCK/BMAL1 heterodimer.
Mol. Cell. Biol. 26: 7318.

Matsuo T., Yamaguchi S., Mitsui S., Emi A., Shimoda F., and Okamura H. 2003. Control mechanism of the circadian clock for timing of cell division. Science 302: 255.

McDearmon E.L., Patel K.N., Ko C.H., Walisser J.A., Schook A.C., Chong J.L., Wilsbacher L.D., Song E.J., Hong H.K., Bradfield C.A., and Takahashi J.S. 2006. Dissecting the functions of the mammalian clock protein BMAL1 by tissue-specific rescue in mice. Science 314: 1304.

Mitsui S., Yamaguchi S., Matsuo T., Ishida Y., and Okamura H. 2001. Antagonistic role of E4BP4 and PAR proteins in the circadian oscillatory mechanism. Genes Dev. 15: 995.

Moore R.Y. and Eichler V.B. 1972. Loss of circadian adrenal corticosterone rhythm following suprachiasmatic nucleus lesion in the rat. J. Comp. Neurol. 146: 1.

Okamura H. 2004. Clock genes and cell clocks: Roles, actions and mysteries. J. Biol. Rhythms 19: 388.

Panda S., Antoch M.P., Miller B.H., Su A.I., Schook A.B., Straume M., Schultz P.G., Kay S.A., Takahashi J.S., and Hogenesch J.B. 2002. Coordinated transcription of key pathways in the mouse by the circadian clock. Cell 109: 307.

Pando M.P., Morse D., Cermakian N., and Sassone-Corsi P. 2002. Phenotypic rescue of a peripheral clock genetic defect via SCN hierarchical dominance. Cell 110: 107.

Ralph M.R., Foster R.G., Davis F.C., and Menaker M. 1990. Transplanted suprachiasmatic nucleus determines circadian period. Science 247: 975.

Reppert S.M. and Weaver D. 2002. Coordination of circadian timing in mammals. Nature 418: 935.

Schibler U. and Sassone-Corsi P. 2002. A web of circadian pacemakers. Cell 111: 919

Shigeyoshi Y., Taguchi K., Yamamoto S., Takekida S., Yan L., Tei H., Moriya T., Shibata S., Loros J.J., Dunlap J.C., and Okamura H. 1997. Light-induced resetting of a mammalian circadian clock is associated with rapid induction of the mPerl transcript. Cell 91: 1043 .

Siepka S.M., Yoo S.H., Park J., Song W., Kumar V., Hu Y., Lee C., and Takahashi J.S. 2007. Circadian mutant Overtime reveals F-box protein FBXL3 regulation of cryptochrome and period gene expression. Cell 129: 1011.

Stephan F.K. and Zucker I. 1972. Circadian rhythms in drinking behavior and locomotor activity are eliminated by suprachiasmatic lesions. Proc. Natl. Acad. Sci. 54: 1521

Storch K.F., Lipan O., Leykin I., Viswanathan N., Davis F.C., Wong W.H., and Weitz C.J. 2002. Extensive and divergent circadian gene expression in liver and heart. Nature 417: 78.

Sujino M., Matsumoto K., Yamaguchi S., van der Horst G., Okamura H., and Inouye S.I.T. 2003. Suprachiasmatic nucleus grafts restore circadian behavioral rhythms of genetically arrhythmic mice. Curr. Biol. 13: 664.

Terazono H., Mutoh T., Yamaguchi S., Kobayashi M., Akiyama M., Udo R., Ohdo S., Okamura H., and Shibata S. 2003. Adrenergic regulation of clock gene expression in the mouse liver. Proc. Natl. Acad. Sci. 100: 6795.

Yagita K., Tamanini F., van der Horst G., and Okamura H. 2001. Molecular mechanisms of the biological clock in cultured fibroblasts. Science 292: 278.

Yagita K., Tamanini F., Yasuda M., Hoeijimakers J.H.J., van der Horst G.T.J., and Okamura H. 2002. Nucleocytoplasmic shuttling and mCRY dependent inhibition of ubiquitination of the mPER2 clock protein. EMBO J. 21: 1301.

Yamaguchi S., Isejima H., Matsuo T., Okura R., Yagita K., Kobayashi M., and Okamura H. 2003. Synchronization of cellular clocks in the suprachiasmatic nucleus. Science 302: 1408.

Yamaguchi S., Kobayashi M., Mitsui S., Ishida Y., van der Horst G.T.J., Suzuki M., Shibata S., and Okamura H. 2001. Real time monitoring of clock gene expression in the living mouse. Nature 409: 684.

Yamamoto Y., Yagita Y., and Okamura H. 2005. Role of cyclic mPer2 expression in mammalian cellular clock. Mol. Cell. Biol. 25: 1912 


\section{$\overbrace{\text { CSH' }}^{\infty}$ Cold Spring Harbor Symposia SYMPOSIA on Quantitative Biology}

\section{Suprachiasmatic Nucleus Clock Time in the Mammalian Circadian System}

H. Okamura

Cold Spring Harb Symp Quant Biol 2007 72: 551-556

Access the most recent version at doi:10.1101/sqb.2007.72.033

References This article cites 40 articles, 16 of which can be accessed free at:

http://symposium.cshlp.org/content/72/551.full.html\#ref-list-1

License

Email Alerting Receive free email alerts when new articles cite this article - sign up in the box at the Service top right corner of the article or click here.

To subscribe to Cold Spring Harbor Symposia on Quantitative Biology go to: http://symposium.cshlp.org/subscriptions 